\title{
Pararhabdodon isonensis and Tsintaosaurus spinorhinus: a new clade of lambeosaurine hadrosaurids from Eurasia
}

\author{
Albert Prieto-Marquez ${ }^{\mathrm{a}, *}$, Jonathan R. Wagner ${ }^{\mathrm{b}}$ \\ ${ }^{a}$ Division of Paleontology, American Museum of Natural History, Central Park West at 79th, New York, NY 10024-5192, USA \\ backson School of Geosciences, The University of Texas at Austin, 1 University Station C1100, Austin, Texas 78712-1101, USA
}

\section{A R T I C L E I N F O}

\section{Article history:}

Received 2 December 2008

Accepted in revised form 24 June 2009

Available online 3 July 2009

\section{Keywords:}

Hadrosauridae

Lambeosurinae

Dinosauria

Tsintaosaurus

Pararhabdodon

Koutalisaurus

\begin{abstract}
A B S T R A C T
We present new anatomical information showing that Koutalisaurus kohlerorum, from the Maastrichtian of Lleida Province, northeastern Spain, is most probably the junior synonym of Pararhabdodon isonensis from the same region. Dentary and maxillary characters previously considered as autapomorphies of $K$. kohlerorum and $P$. isonensis, respectively, are shown to be synapomorphies uniting the latter with Tsintaosaurus spinorhinus from the Campanian of the Wangshi Group, Shandong Province, China.

This study provided conclusive evidence of the presence of the Lambeosaurinae in Europe. Tsintaosaurus spinorhinus and Pararhabdodon isonensis were inferred to form a clade of basal lambeosaurines characterized by a maxilla with an elevated articular facet for the jugal (continuous with the ectopterygoid ridge) and an extremely medially projected symphyseal region of the dentary. This clade originated in Asia during the middle or late Campanian. Pararhabdodon isonensis or its ancestors migrated from Asia to the Iberian island of the European archipelago. Reconstruction of ancestral areas by Fitch parsimony attributes the European occurrence of $P$. isonensis to a single dispersal event from Asia no later than middle to late Campanian.
\end{abstract}

(c) 2009 Elsevier Ltd. All rights reserved.

\section{Introduction}

Lambeosaurine hadrosaurids are the most anatomically derived ornithopod dinosaurs (Horner et al., 2004). They are unique among ornithischians in having posterodorsally located nasal passages (Weishampel, 1981; Wagner, 2004) enshrouded by hollow supracranial crests. These crests manifest a bewildering diversity of shapes and sizes; their function may have been species recognition and sexual display (Hopson, 1975; Evans, 2006). The fossil record of the Lambeosaurinae in the uppermost Cretaceous (CampanianMaastrichtian) of North America is extensive (Wagner, 2001; Lund and Gates, 2006).

The first published Asian lambeosaurine was Tsintaosaurus spinorhinus Young, 1958, from the Jingangkou Formation (Hu et al., 2001) of the Wangshi Group of Shandong, China. Weishampel and Horner (1990) were unconvinced that the crest of this animal was hollow, and regarded it as a chimera composed of hadrosaurine and lambeosaurine material. Taquet (1991) considered it synonymous with non-crested Tanius, suggesting that the upright nasals resulted from post-mortem distortion. Buffetaut and Tong-Buffetaut

\footnotetext{
* Corresponding author.

E-mail address: amarquez@bio.fsu.edu (A. Prieto-Marquez).
}

(1993, 1995) reexamined the original material of Tsintaosaurus spinorhinus, and demonstrated that it belonged to a crested lambeosaurine as originally described (Young, 1958). New discoveries and new interpretations have since revealed an abundance of Asian lambeosaurines (Godefroit et al., 2000, 2001, 2003; Godefroit et al., 2004a; Alifanov et al., 2004).

Hadrosaurids are poorly known in Europe (López-Martínez et al., 2001; Prieto-Márquez et al., 2006, 2007). Pararhabdodon isonensis, from the upper Maastrichtian Tremp Formation of Spain (Casanovas-Cladellas et al., 1993; Casanovas et al., 1999a), has been considered a lambeosaurine based on the presence of a haemal sulcus on the ventral surface of the sacrum and a moderate distal expansion of the ischium (Casanovas et al., 1999a). Both of these character states are ancestral for hadrosaurs, and the haemal sulcus is intraspecifically variable in some taxa (Godefroit et al., 1998; Prieto-Marquez, pers. data). Head (2001) felt that the evidence for lambeosaurine affinities presented by Casanovas et al. (1999a) was insufficient, and noted that the animal's relatively low tooth count might exclude it from the Hadrosauridae. Prieto-Márquez et al. (2006) presented a formal phylogenetic analysis in which Pararhabdodon isonensis was found to be the sister taxon to the Hadrosauridae, based on the presence of a maxilla with three or four foramina, only 35-40 maxillary alveolar positions, and strongly dorsally arched cervical postzygapophyses. 
An isolated dentary, IPS SRA 27 (Fig. 1A and B) from Les Llaus locality (Tremp Formation, northeastern Spain) was referred to Pararhabdodon isonensis by Casanovas et al. (1999a). Prieto-Márquez et al. (2006) rejected this referral, because the site is separated from the Pararhabdodon isonensis locality, and the latter produced no dentary material. The latter authors noted a distinctive autapomorphy of IPS SRA 27, a symphysial process that projects medially to an extreme not seen in other hadrosaurs (Fig. 1A and B). On the basis of this character, Prieto-Márquez et al. (2006) recognized the specimen as the type of a new genus and species, Koutalisaurus kohlerorum.

The presence of lambeosaurine hadrosaurids in Europe represents a significant range extension for the clade (Casanovas et al., 1999a; Head, 2001; Prieto-Márquez et al., 2006). The European uppermost Cretaceous dinosaur fauna is poorly known, but appears to be taxonomically distinct from that of Asiamerica (Weishampel et al., 2004). The presence of a signature Asiamerican taxon like the Lambeosaurinae might indicate that some of the perceived differences are the result of missing data, rather than real zoogeographic provincialism. Here, we revisit the synonymy of Pararhabdodon isonensis and Koutalisaurus kohlerorum, reanalyze the phylogenetic relationships of these taxa, and consider the biogeographic ramifications of the result.

Institutional acronyms: CMN, Canadian Museum of Nature, Ottawa, Ontario; FGGUB, Faculty of Geology and Geophysics, University of Bucharest, Bucharest, Romania; IPS, Museum of the Institut Català de Paleontologia (formerly the Institute of Paleontology "Miquel Crusafont"), Sabadell, Spain; IVPP, Institute of Vertebrate Palaeontology and Palaeoanthropology, Beijing, China; MCD, Museu de la Conca Dellà, Isona, Spain; MOR, Museum of the Rockies, Bozeman, Montana; NHM, National History Museum, London, United Kingdom; SRA, Sant Romà d'Abella, Spain.

\section{Materials and methods}

One of us (APM) examined all of the material referred to Pararhabdodon isonensis and Koutalisaurus kohlerorum housed at the IPS and MCD, as well as the holotype and referred material of Tsintaosaurus spinorhinus at the IVPP. The phylogenetic relationships of Pararhabdodon isonensis (including IPS SRA 27) and Tsintaosaurus spinorhinus were reassessed in a broad analysis including 39 hadrosaurids and ten non-hadrosaurid hadrosauroids, with two non-hadrosauroids, Iguanodon bernissartensis and Ouranosaurus nigeriensis, included to root the tree (Wiley, 1981; Maddison et al., 1984). A separate analysis was also performed, in which Koutalisaurus kohlerorum and Pararhabdodon isonensis were scored separately. The character data consist of 299 discrete observations of osteological morphology. Of these, 196 are binary, 99 are multistate unordered, and four are ordered multistate characters (Appendices 1 and 2).

We conducted a Bayesian analysis using the Mk maximum likelihood model for discrete morphological data presented by Lewis (2001) and implemented in MrBayes version 3.1.2 (Huelsenbeck and Ronquist, 2001). No priors were specified other than the default (flat) priors for the model, and rates of character change were assumed to be equal. The analysis used six chains run for $10,000,000$ generations, sampled every 100 generations. Trees from the first 100,000 generations were discarded as "burn-in," and stationarity was judged to have been achieved when the standard deviation of split frequencies reached 0.005. Regarding the subject of the present paper, the results of this analysis are consistent with those of parsimony analysis (result available at http://www. morphbank.net/Show/?id=473174) of the same dataset using PAUP* 4.0b10 (Swofford, 2002). Likewise, Bayesian analysis using Pararhabdodon isonensis and Koutalisaurus kohlerorum separately recovered a clade composed of these two taxa and Tsintaosaurus spinorhinus (available at http://www.morphbank.net/Show// $\mathrm{id}=473173$ ). Ancestral areas were reconstructed using Fitch parsimony (Fitch, 1971) in MacClade 4.0 (Maddison and Maddison, 2003), and Dispersal-Vicariance with DIVA 1.1 (Ronquist, 1996, 1997), to infer the historical biogeography of Pararhabdodon isonensis and other hadrosaurs (results available online at http:// www.morphbank.net/Show/?id=473175 and http://www. morphbank.net/Show/?id=473176).

\section{Systematic paleontology}

Dinosauria Owen, 1842

Ornithischia Seeley, 1888

Hadrosauroidea Sereno, 1986 (new definition)
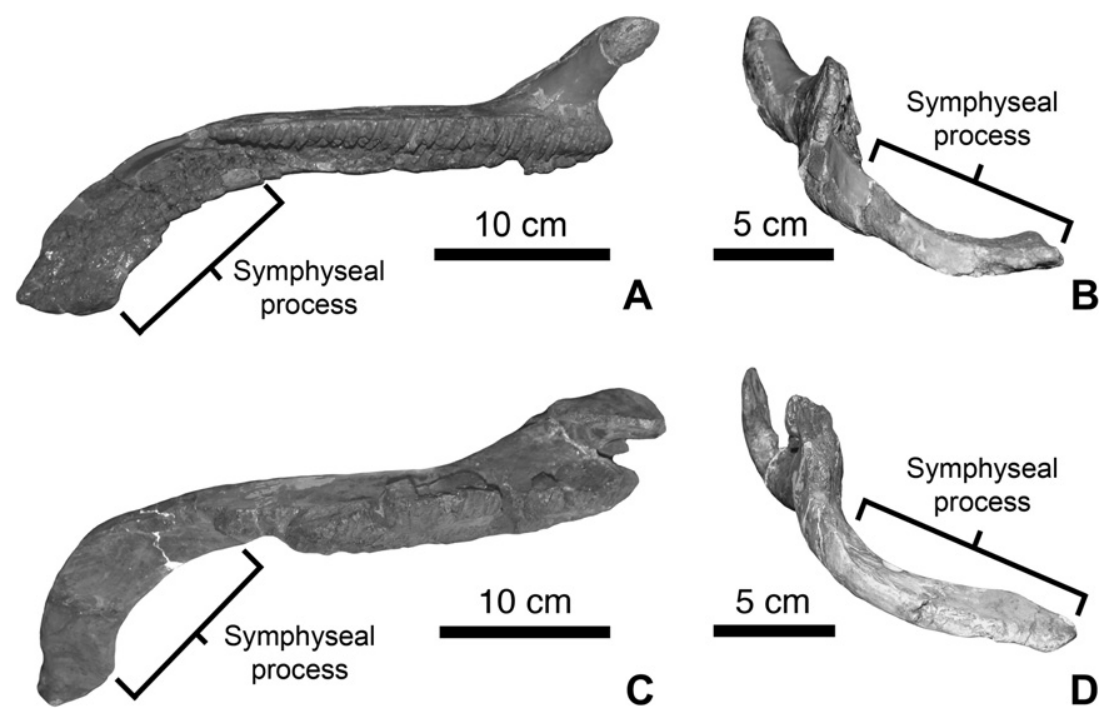

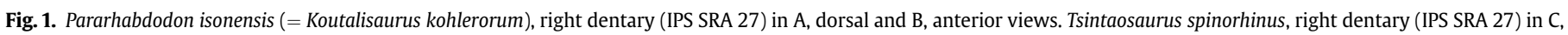
dorsal and D, anterior views. 
Hadrosauridae Cope, 1870 (sensu Prieto-Marquez, 2008) Lambeosaurinae Parks, 1923 (sensu Prieto-Marquez, 2008)

Pararhabdodon Casanovas-Cladellas et al., 1993

Pararhabdodon isonensis Casanovas-Cladellas et al., 1993

Synonymy. Pararhabdodon isonense Casanovas-Cladellas et al., 1993; Koutalisaurus kohlerorum Prieto-Márquez et al., 2006.

Revised diagnosis. Differs from all other hadrosaurids, except Tsintaosaurus spinorhinus, in elevation of jugal facet of maxilla such that ventralmost extent is well above level of lateral margin of ectopterygoid shelf, maxilla forms acute embayment extending ventral to jugal process between jugal facet and ectopterygoid shelf; jugal facet of maxilla anteroposteriorly foreshortened, likely with correspondingly anteroposteriorly narrow anterior jugal; anterior dentary with symphysial process projecting medially such that distance between symphysis and lateral surface of dentary is three times labiolingual thickness of alveolar chamber. Differs from Tsintaosaurus spinorhinus in broader, subrectangular anterodorsal region of the maxilla.

Holotype. IPS SRA 1: nearly complete mid-caudal cervical vertebra.

Hypodigm. IPS SRA 15, left humerus; IPS SRA 16, proximal fragment of left scapula; IPS SRA 18, anterior or middle cervical vertebra; MCD 4730, anterior cervical vertebrae; IPS SRA 25, middle cervical vertebra; IPS SRA 18, posterior middle cervical vertebra; IPS SRA 13, centrum of dorsal vertebra; MCD 4731, anterior dorsal vertebra; IPS 693-13, IPS SRA 12 and 20, posterior middle dorsal vertebrae; IPS SRA 17, complete caudal vertebra; IPS SRA 22, nearly complete right maxilla; IPS SRA 23, posterior half of left maxilla; IPS SRA 24, nearly complete sacrum; IPS 693-12, fragment of proximal rib; IPS SRA 26, distal end of right ischium; IPS SRA 27, left dentary with incomplete coronoid process, lacking teeth, holotype of Koutalisaurus kohlerorum.

Occurrence. Sant Romà d'Abella site near the town of Isona (all specimens excluding IPS SRA 27) and Les Llaus site near the town of Abella de la Conca (IPS SRA 27), Lleida Province, Catalunya, northeastern Spain. Both localities are in the Upper Cretaceous Tremp Formation (probably upper Maastrichtian), but 750 meters apart horizontally and 9 meters stratigraphically.

\section{Taxonomic revisions}

\subsection{Status of Koutalisaurus kohlerorum}

Dentaries referred to Tsintaosaurus spinorhinus (Young, 1958; Fig. 1C and D) are unusual in having a symphysial process that is extremely elongated medially, such that the distance between the symphysis and the lateral side of those dentaries is at least three times the mediolateral width of the rest of the element. They share this condition, as well as a low tooth count at similar overall size (Young, 1958), with IPS SRA 27. In fact, the dentaries of Koutalisaurus kohlerorum and Tsintaosaurus spinorhinus are virtually indistinguishable (Fig. 1), apart from the posterodorsal orientation of the coronoid process in IPS SRA 27, which appears to be an artifact of preparation (Prieto-Márquez et al., 2006).

This leaves Koutalisaurus kohlerorum lacking autapomorphies, and some authorities might therefore consider it a nomen dubium. We find this approach to paleontological taxonomy rigid and impractical. Barring the discovery of two hadrosaur species bearing this unusual dentary morphology in the Tremp Formation, we feel that there is sufficient evidence that IPS SRA 27 represents a distinct (albeit poorly known) element of the Tremp fauna. If no other name is appropriate, then we see no problem with using Koutalisaurus kohlerorum.

Koutalisaurus kohlerorum might be a junior synonym of Tsintaosaurus spinorhinus. A large archosaur species spanning the spatial and temporal range this synonymy implies would be unprecedented. It is more conservative and practical to maintain a distinction between the two taxa until additional, definitive material is recovered. On the other hand, Pararhabdodon isonensis is not so dramatically separated from Koutalisaurus kohlerorum. As these two taxa lack overlapping material, there is no direct evidence for or against their synonymy.

\subsection{Status of Pararhabdodon isonensis}

Despite sharing an unusual conformation of the maxillary-jugal articulation (see below), Pararhabdodon isonensis is diagnostically distinct from Tsintaosaurus spinorhinus. In the former, the lateral face of the maxilla between the posterior margin of the jugal articulation surface and the anterodorsal border of the premaxillary shelf is much longer anteroposteriorly than in Tsintaosaurus spinorhinus. As with Koutalisaurus kohlerorum, the significant spatiotemporal separation of these taxa also argues for maintaining their distinction.

The stratigraphic arguments against association of IPS SRA 27 with the hypodigm of Pararhabdodon isonensis (Prieto-Márquez et al., 2006) were intended to demonstrate that the relevant material most likely belonged to different individual organisms. In a stratigraphic sense, the separation of 750 meters horizontally and 9 meters in vertical section seems almost trivial, and does not preclude the remains belonging to the same species. Although the hypodigms of Koutalisaurus kohlerorum and Pararhabdodon isonensis share no overlapping referred skeletal elements, they each share unique, derived character states with Tsintaosaurus spinorhinus. This constitutes circumstantial evidence supporting synonymy of Pararhabdodon isonensis and Koutalisaurus kohlerorum. Such a synonymy introduces no synapomorphy combinations not already observed among known hadrosaurs, and is therefore "safe" in a manner analogous to Safe Taxonomic Reduction (Wilkinson and Benton, 1995).

We therefore refer dentary IPS SRA 27 to Pararhabdodon isonensis, as proposed by Casanovas et al. (1999a), and accept this taxon as a senior subjective synonym of Koutalisaurus kohlerorum. To maintain taxonomic separation would be misleading: nonspecialists conducting research of a broad scope cannot be expected to know that the distinction was maintained in an effort to be "conservative," and would likely reach the erroneous conclusion that there is positive evidence for more than one hadrosaur in the Tremp Formation. On the other hand, if our synonymy is overturned by new discoveries, the resulting separation of these taxa will reflect the evidence, and will thus be a meaningful and welcome improvement in hadrosaurid taxonomy.

\section{Comparisons with other western European hadrosaurids}

Prieto-Márquez et al. (2006) summarized the anatomical differences between IPS SRA 27 and the dentaries of hadrosauroids from southern France (Paris and Taquet, 1973; Le Loeuff et al., 1993, 1994; Laurent et al., 1997, 1999) and the Iberian Peninsula (Company et al., 1998; Casanovas et al., 1999b). Additional published material from the Upper Maastrichtian of southern France (Bexen locality, Corbières, Le Loeuff et al., 1993, 1994) was referred to Pararhabdodon sp. by Laurent et al. (1997). We find no osteological evidence to support this referral; the postcranial material is consistent with that of Pararhabdodon isonensis, but does not appear diagnostic. The referred 'maxilla' appears to be the posterior 
portion of the alveolar process of a dentary where it extends as a process medial to the Meckelian Fossa. If it is a maxilla, the unusual anterior process and abrupt posteromedial curvature are unprecedented autapomorphies not at all consistent with Pararhabdodon isonensis.

An isolated hadrosaurid ilium, collected from the Upper Maastrichtian Blasi 3 fossiliferous horizon in the Conques Formation near Arén (Huesca Province, Aragón, northeastern Spain), was referred to the Lambeosaurinae by Cruzado-Caballero et al. (2005 2007) based on the presence of an arcuate and ventrally deflected preacetabular process, a relatively deep ilium, and an elongate, pendant iliac supraacetabular process (or 'antitrochanter'; Cruzado-Caballero et al., 2005). The angle of ventral deflection of the preacetabular process is pronounced $\left(30^{\circ}\right.$ or more from the horizontal) in all hadrosaurids and many non-hadrosaurid hadrosauroids (character 243). The length/depth ratio was calculated by Cruzado-Caballero et al. (2005) using the total length of the ilium. Based only on the central body, a relatively deep ilium (length/ depth ratio greater than 0.8 ) is present not only in all lambeosaurines except Parasaurolophus cyrtocristatus, but also in the saurolophine Brachylophosaurus canadensis, and all non-hadrosaurid iguanodontoideans sampled for this study (character 246). Extension of the supraacetabular process ventral to the middle of the iliac central body is a synapomorphy of the Hadrosauridae (PrietoMarquez, 2008), suggesting that the Blasi 3 ilium is either referable to the Hadrosauridae or it represents the sister taxon to that clade. It is not, however, diagnostically lambeosaurine.

A hadrosaurid from the Blasi 1 horizon (López-Martínez et al., 2001) has a jugal with an anteroposteriorly abbreviated, dorsoventrally deep maxillary process and a shallow quadrate process with a correspondingly prominent "scallop" (López-Martínez et al., 2001), similar to that seen in Tsintaosaurus spinorhinus. Regarding the Blasi 1 dentary, Prieto-Márquez et al. (2006) determined that this element is not referable to Pararhabdodon isonensis because, judging from the publish image in López-Martínez et al. (2001), it lacks the characteristic long medial projection seen in IPS SRA 27.

Finally, several new fossil localities have been discovered in recent years corresponding to the Upper Maastrichtian Tremp Basin of Lleida Province, northeastern Spain. These localities, such as Euroda Nord, Serrat del Corb, Molí del Baró, and particularly the Basturs bonebed, have provided numerous postcranial and a few partial cranial remains from hadrosaurids, some of which have been tentatively referred to Lambeosaurinae (Gaete et al., 2007; Martín et al., 2007; Prieto-Marquez et al., 2007). Pending a detailed study of those remains (many of which await preparation), preliminary comparisons identified a very small dentary in the sample of Basturs with a symphyseal region nearly as medially elongated as in IPS SRA 27. The study in progress of these new materials should reveal more clues on their affinities, in particular whether they may represent additional specimens of Pararhabdodon isonensis.

\section{Discussion and conclusions}

\subsection{Morphology of the maxilla-jugal joint}

Besides the unique morphology of the mandibular symphysis, the other strongest similarity between Pararhabdodon isonensis and Tsintaosaurus spinorhinus lies at the junction of the maxilla and jugal. The maxillary jugal articulation, and the peribuccal foramina that pass beneath it, have undergone a complex phylogenetic transformation in hadrosauroids (Wagner, 2001; Prieto-Márquez et al., 2006, character 26; Wagner and Lehman, 2009). We distinguish four different morphological conditions of the jugal articulation surface in the maxilla of iguanodontoidean ornithopods. In the ancestral iguanodontoidean morphology, exemplified by Mantellisaurus atherfieldensis (e.g., NHM R5764, available at http://www.morphbank. net/Show/?id=461305), there is an elongate and pendant, fingerlike jugal process (Norman, 1986, 2002) separated from the lateral margin of the (posteroventrally inclined) ectopterygoid shelf below by a parasagittal sulcus. The shelf does not curve dorsally to meet the jugal process, but tapers into the lateral surface of the bone, forming the ventral margin of the sulcus.

A different condition occurs in non-hadrosaurid hadrosauroids, such as Bactrosaurus johnsoni, Gilmoreosaurus mongoliensis, and Telmatosaurus transsylvanicus. In these forms, the articular facet for the jugal is perched above the ectopterygoid ridge. More specifically, the jugal articular facet lies on a promontorium that is elevated and detached from to the anterior region of the ectopterygoid shelf. A thick ridge limits the posterior extent of the jugal articular facet, where the promontorium protrudes posteriorly into a well-defined apex (Fig. 2A and B). The posteriormost peribuccal foramina (typically three) lie in a cluster near the anterior limit of the ectopterygoid shelf.

A different, third condition is present in Hadrosauridae, where the jugal facet forms a low boss on the lateral face of the maxilla, with its ventral margin continuous with the edge of the ectopterygoid shelf. The dorsal surface of the shelf curves abruptly but smoothly into the posterior face of the jugal articulation, and the posterior end of the line of peribuccal foramina is formed by a single enlarged foramen, opening anterolaterally from the ventrolateral margin of the jugal process (Fig. 2C and D).

The peribuccal foramina of ornithischians conducted serial branches of a neurovascular package from the antorbital space to the buccal space (Davies, 1983; Witmer, 1997). Progressive reduction of the antorbital fenestra during hadrosauroid evolution enclosed some of the contents of the antorbital space, including this package, within the maxillary neurovascular canal (Davies, 1983; Witmer, 1997; Wagner, 2001). The posterior cluster of peribuccal foramina conducted a small swarm of neurovascular branches, and the sulcus between the jugal-maxilla joint and ectopterygoid shelf in non-hadrosaurid hadrosauroids probably accommodated the posteriormost branch in the series. During the evolution of the hadrosauroid cheek complex, the jugal-maxillary joint expanded greatly, to form matching broad surfaces on the maxilla and jugal. The jugal facet of the maxilla eventually extended to the margin of the ectopterygoid shelf, bridging the sulcus, and trapping the posteriormost neurovascular branches such that the sulcus and the posteriormost branch were completely enclosed in bone. All of the posterior branches exited the bone through a common, enlarged posterior foramen on the ventrolateral wall of the promontorium for the jugal facet in hadrosaurids.

In the phylogenetic analyses of Prieto-Márquez et al. (2006), Pararhabdodon isonensis was scored as having the ancestral hadrosauroid condition of the maxilla-jugal joint, with an elevated promontorium separated from the margin of the ectopterygoid shelf by a sulcus. This coding greatly influenced the position of Pararhabdodon isonensis, causing it to fall outside of the Hadrosauridae. Comparison of the maxillae of Tsintaosaurus spinorhinus and Pararhabdodon isonensis reveals that this scoring was erroneous. These species share a modified version of the hadrosaurid condition, in which the ectopterygoid shelf extends to the jugal facet as a continuous, albeit recurved lip, and the posterior end of the line of peribuccal foramina is formed by an enlarged foramen as in hadrosaurids (Fig. 2E and F).

In at least some lambeosaurines, the maxilla-jugal joint is set somewhat higher than the surface of the ectopterygoid shelf. However, in Tsintaosaurus spinorhinus and Pararhabdodon isonensis, the maxilla-jugal joint is set very high on the lateral surface of the 

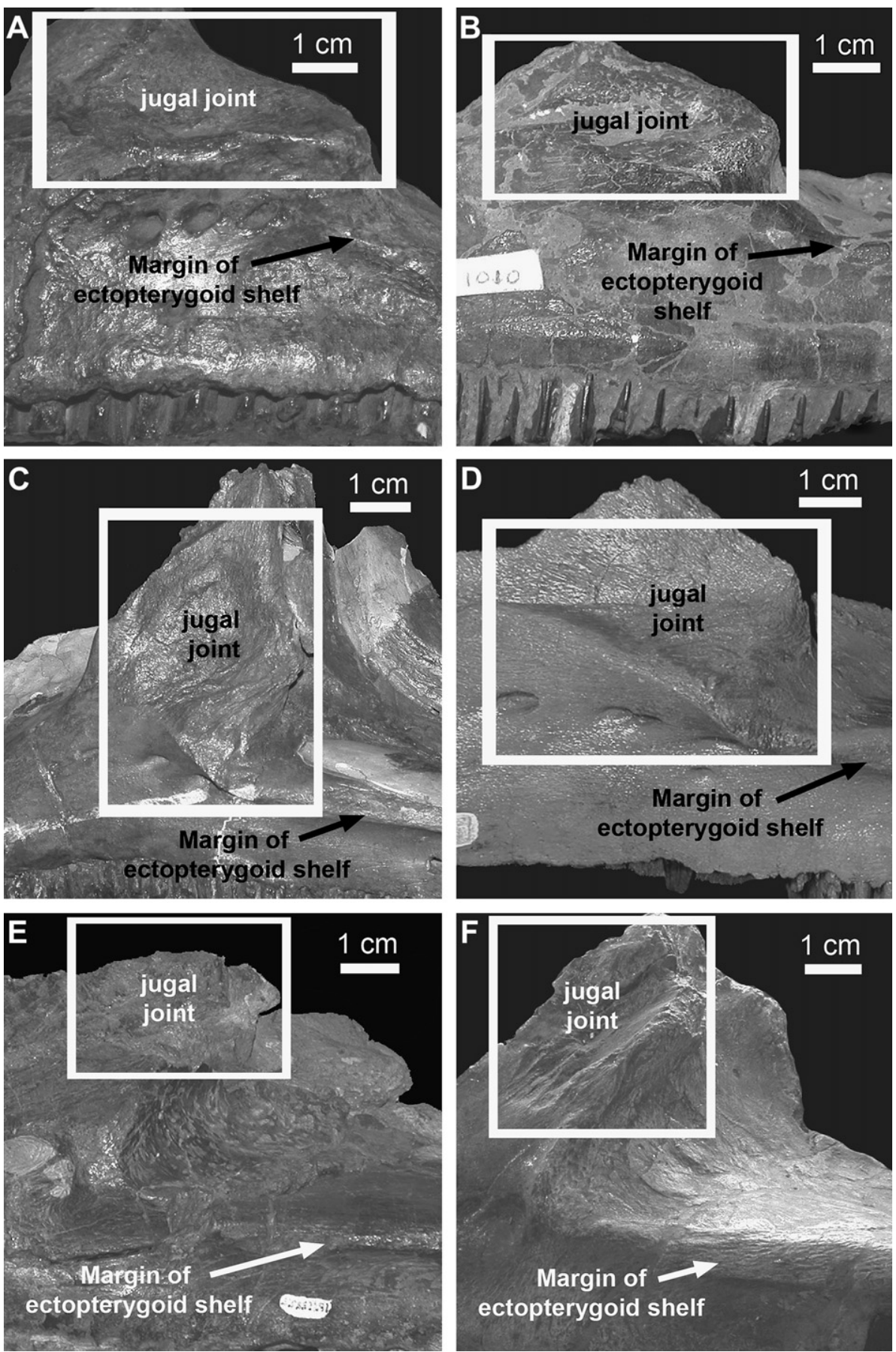

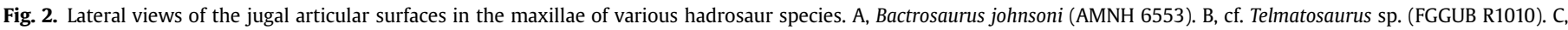

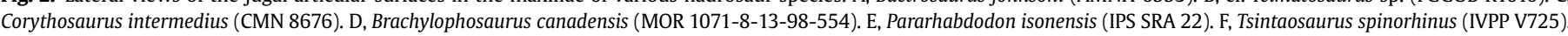

bone, and the ventral jugal tubercle of the maxilla is anterior to the dorsal tubercle, as in lambeosaurines (Wagner and Lehman, 2009). These conditions are taken to such an extreme that the maxilla forms an acutely curved embayment between the jugal articulation and the edge of the ectopterygoid shelf at the anteromedial corner of the coronoid fossa (Fig. 2E and F). This embayment is superficially similar to the ancestral sulcus in shape and gross morphology, but can be distinguished because the embayment is bounded anteroventrally by the raised edge of the ectopterygoid shelf, and does not open onto the buccal face of the maxilla as in the ancestral condition. In our phylogenetic analysis, the morphology exhibited by Tsintaosaurus spinorhinus and Pararhabdodon isonensis was scored as a third character state (in an unordered character). Parsimony ancestral state reconstruction shows that this condition evolved from the one seen in other hadrosaurids, and not directly from the plesiomorphic hadrosauroid condition.

The shape of the maxillary jugal facet itself, steeply posterodorsally inclined and anteroposteriorly narrow, is also similar in Pararhabdodon isonensis and Tsintaosaurus spinorhinus, but this was not scored as a separate character in the analysis. Young (1958, Fig. 41) described a pair of jugals with greatly dorsoventrally 
expanded maxillary articulations and relatively shallow, "scalloped" quadrate processes, but did not refer them to Tsintaosaurus spinorhinus. The shape of the jugal facet of the maxilla is directly related to the shape of the maxillary process of the jugal (contra Head, 2001), and these jugals almost certainly belong to that species. Given the similarity of the jugal facet of the maxilla, it seems likely that Pararhabdodon isonensis sported a similar jugal. The anterior jugal of Olorotitan ararhensis (Godefroit et al., 2003), and Hypacrosaurus altispinus (e.g., ROM 789) is also anteroposteriorly narrow and posterodorsally oriented, but its articulation with the maxilla is not elevated significantly above the ectopterygoid shelf.

\subsection{Phylogenetic hypothesis}

Our phylogenetic analysis recovered a sister group relationship between Pararhabdodon isonensis and Tsintaosaurus spinorhinus, forming a clade with other lambeosaurines to the exclusion of Jaxartosaurus aralensis and Aralosaurus tuberiferus (Fig. 3). The analysis with Koutalisaurus kohlerorum and Pararhabdodon isonensis coded separately resulted in essentially the same tree, but $P$. isonensis, K. kohlerorum, and Tsintaosaurus spinorhinus fell into an unresolved trichotomy (available at http://www.morphbank.net/ Show/?id=473173). Pairing of Pararhabdodon isonensis and Tsintaosaurus spinorhinus is supported by the following unambiguous

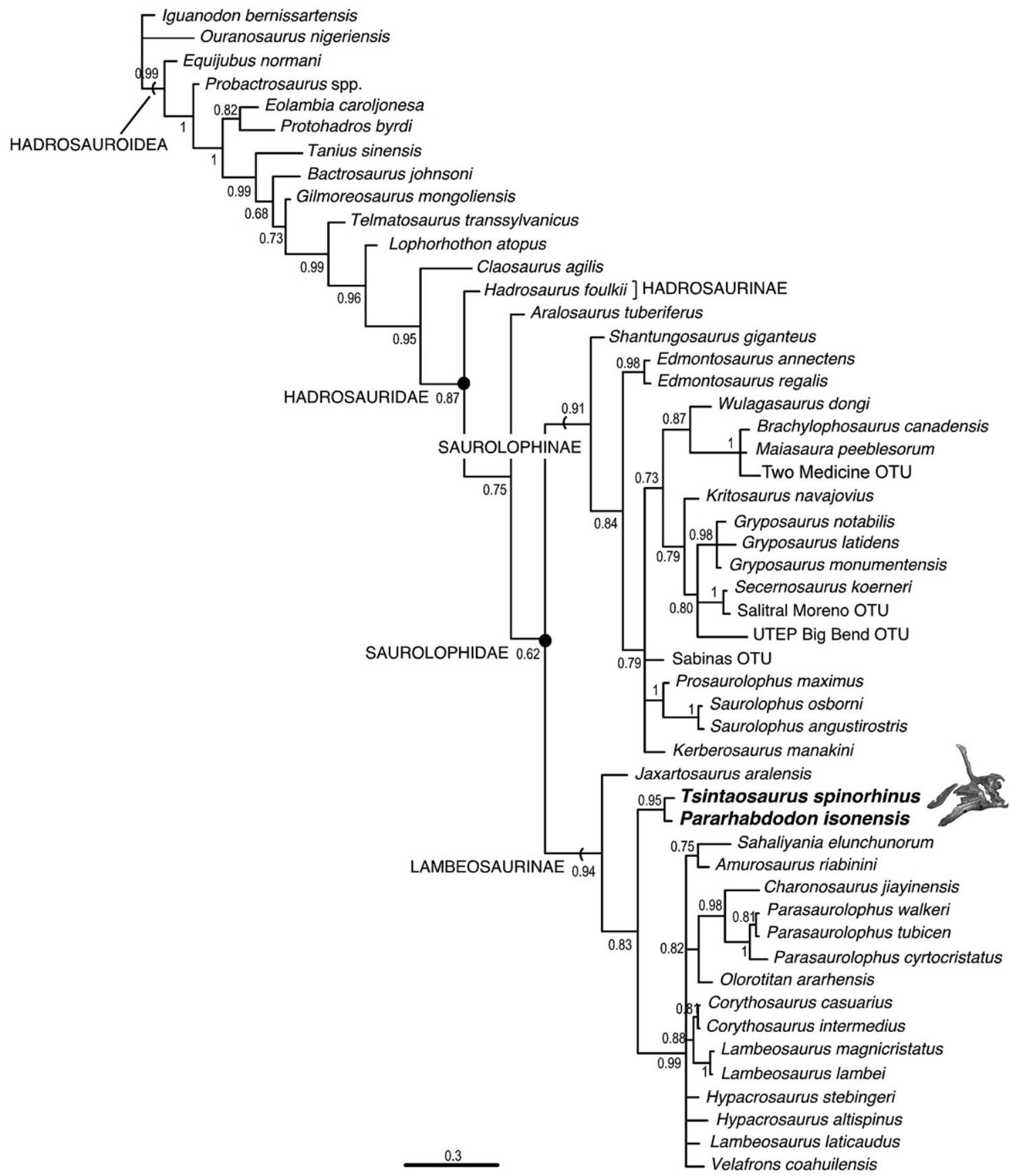

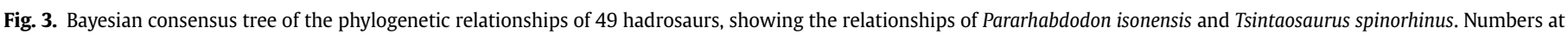
nodes represent Bayesian posterior probabilities. 
synapomorphies: long medial projection of the symphysial region of the dentary (character 42-2), anterior edentulous region of the dentary for articulation with the predentary nearly straight (character 45-0), and a dorsally elevated maxilla-jugal joint (character 100-3). One additional ambiguous synapomorphy supports this group under delayed transformation character optimization (Swofford, 2002): ventral deflection of the anterior edentulous region of the dentary greater than $25^{\circ}$ (character 40-2).

We agree with Casanovas et al. (1999a), that Pararhabdodon isonensis is a lambeosaurine. Characters supporting inclusion of $P$. isonensis within the Lambeosaurinae include: absence of maxillary rostromedial process (character 92-1); high dorsal maxillary process (character 99-1); and ratio between the length of the proximal edentulous slope of the dentary and that of the dental battery ranging from 0.20 to 0.31 (character 37-1). Inclusion of $P$. isonensis within the Hadrosauridae are: dentary with more than 30 tooth positions (character 1-1); loss of all but the primary ridge of dentary tooth crowns (character 6-3); maxilla with more than 32 tooth positions (character 16-1); dentary symphysis forming an angle up to $15^{\circ}$ with the lateral side of the rostral half of the element (character 43-1); long axis of the occlusal plane of the dentary set parallel to the lateral side of the element (character 521 ); posterior end of the dental battery of the dentary located posterior to the coronoid process (character 54-2); and maxillary foramina forming either a row or cluster that is oriented anterodorsally, ventral to the jugal articulation (character 101-1). We also concur with Young (1958), Buffetaut and Tong-Buffetaut (1993, 1995) that Tsintaosaurus spinorhinus is a lambeosaurine, based on the presence of a relatively short ectocranial surface of the frontal with a length/width ratio greater than 0.4 and up to 0.8 (character 153-1), and a sagittal crest of the parietal that extends along the entire length of the element, fading away at the anterior region where the parietal is anteroposteriorly shorter than it is wide (character 158-1).

\subsection{Biogeographic implications}

Pararhabdodon isonensis greatly expands the documented distribution of known species of the Lambeosaurinae and, by extension, the Hadrosauridae. While hadrosaurids dominated the Asiamerican ornithopod fauna during the Maastrichtian, the European archipelago appears to have served as a refuge for early offshoots of the hadrosauroid lineage, as it apparently did for other taxa (Nopcsa, 1923, 1934). Apart from Pararhabdodon isonensis (and possibly the form from Blasi), all European hadrosauroids lie outside the Hadrosauridae, including the Romanian Telmatosaurus transsylvanicus (Nopcsa, 1903; Weishampel et al., 1993); a closely related, undescribed species from Italy (Dalla Vecchia, 2001); several partial mandibles from Spain (Company et al., 1998; Casanovas et al., 1999b); and a number of other fragmentary specimens, none of which is diagnostically hadrosaurid (reviewed in Dalla Vecchia, 2006).

Reconstruction of ancestral areas (phylograms available at http://www.morphbank.net/Show/?id=473175 and http://www. morphbank.net/Show/?id=473176) supports an Asian origin for lambeosaurines (Davies, 1983; Brett-Surman, 1989; Godefroit et al., 2000, 2001, 2003, 2004a,b; Head and Kobayashi, 2001; Lehman, 2001), and attributes the European occurrence of Pararhabdodon isonensis to a single dispersal event from Asia no later than middle to late Campanian (see also Casanovas et al., 1999a). Although substantially older (Santonian-Campanian) than the occurrence of $P$. isonensis, the other significant dinosaurian faunal connection between Asia and the European archipelago is the presence of neoceratopsians (Godefroit and Lambert, 2007; Lindgren et al., 2007). These are poorly known, and a single dispersal event cannot be ruled out. Given this, presence of these Asiamerican taxa in the European archipelago is probably incidental, the result of exceptional circumstances. However, it does show that whatever bridges and/or barriers existed between the European archipelago and Asia must have been 'semi-permeable,' permitting lambeosaurines and 'protoceratopsians' through, but not saurolophine hadrosaurids and other typical Asiamerican taxa.

The immigrants were members of groups with deep fossil records in Asia. Likewise, biogeographic analysis indicates that Saurolophinae and at least two other lambeosaurine lineages (one leading to Aralosaurus tuberiferus, the other the sister lineage to the 'tsintaosaurus') were present in Asia at the time of dispersal. These should have shared any opportunity for dispersal available to 'tsintaosaurs.' Alternatively or alongside geographical bridges, there may have also been ecological factors involved, passing only those Asian taxa compatible with European environments, or with intervening habitats. This is highly speculative, and makes untested assumptions about the paleoecology of the migrants. There is no known ecological similarity between 'tsintaosaurs' and 'protoceratopsians,' although the bizarre modification of the anterior mandible of the former might indicate an ecological difference relative to other lambeosaurines.

Dispersal from Asia to Europe may have been essentially stochastic. The inundation of Europe and western Asia, and consequent fragmentation of terrestrial habitat (Casanovas et al., 1999a; Dalla Vecchia, 2006), may have served as a 'leaky' barrier. During their dispersal, Asian taxa may have experienced vicariance driven by insular splitting due to changes in relative sea level in the mosaic of small landmasses that composed the European archipelago (Blakey, 2001; Casanovas et al., 1999a; Dalla Vecchia, 2006). A similar mode of 'island-hopping' dispersal has been suggested for exchange across the Western Interior Seaway of North America during the same interval (Carpenter, 1982). Lambeosaurines and 'protoceratopsians' may have had more opportunities to survive and disperse due to their longer residency and greater lineage diversity in Asia.

\section{Acknowledgements}

For access to specimens under their care, we are most grateful to P. Barrett, B. Battail, M. Brett-Surman, D. Brinkman, K. Carpenter, S. Chapman, J. Cheng, L. Chiappe, Z. Csiki, R. Culbertson, T. Culver, P. Currie, T. Daeschler, R. Dante, C. Delgado, J. Desojo, B. Espinosa, D. Evans, Z. Fang, M. Feuerback, R. Gaete, A. Galobart, E. García, J. Gardner, T. Gates, M. Getty, P. Godefroit, M. del R. Gómez, M. Goodwin, D. Goujet, D. Grigorescu, A. Heckert, A. Henrici, R. Hernández, P. Holroyd, J. Horner, B. Iwama, B. Jacobs, L. Jacobs, Y. Jun, J. Kobalynski, A. Kramarz, M. Lamanna, J. Lamb, W. Langston, T. Lehman, C. de León, L. Liping, J. Li-Young, S. Lucas, E. Lund, K. Madalena, S. Maganuco, P. Makovicky, B. McLeod, C. Mehling, M. Montellano, I. Morrison, C. Muñoz, L. Murray, M. Norell, H. Osmolska, P. Owen, J. Padilla, J. Peel, M. del C. Perrillat, M. Pierce, G. Plodowski, Z. Qin, R. Reisz, L. Rinehart, T. Rowe, K. Sabath, G. Salinas, C. Dal Sasso, C. Serrano, K. Seymour, K. Shepherd, W. Simpson, E. Steurbaut, S. Stuenes, Li Tao, P. Taquet, D. Vineyard, O. Vogel, D. Weishampel, C. Weißbrod, D. Winkler, Xu X., L. Zanno, R. Zapata, K. Zhang, L. Zhong, and R. Zúñiga. We are grateful to Gabe Bever, Rodrigo Gaete, Angel Galobart, David Weishampel, and three anonymous reviewers for their assistance with this manuscript and the underlying research. This work was completed in partial fulfillment of the requirements for a Ph. D. for APM in the Department of Biological Science at Florida State University, and he is especially grateful to his advisor G. Erickson, and committee members W. Parker, D. Swofford, S. Steppan and F. Ronquist. This study was supported by the Charlotte and Walter Kohler Charitable 
Trust, the Department of Biological Science at Florida State University, the National Science Foundation (EAR 0207744 and DBI 0446224 to G. Erickson), the Field Museum of Natural History, the Departments of Geosciences and Civil Engineering and the Graduate School at Texas Tech University, the Science Department at South Plains College, Sigma Xi National Scientific Honorary, the Jackson School of Geological Sciences at the University of Texas at Austin, and an NSF IGERT grant to the Center for Computational Biology and Bioinformatics at UT Austin, and a grant (CGL200507878-C02-01) from the Ministry of Education and Science of Spain presented to A. Galobart.

\section{Appendix. Supplementary data}

Supplementary data associated with this article can be found in the online version, at doi:10.1016/j.cretres.2009.06.005.

\section{References}

Blakey, R.C., 2001. Regional Paleogeographic Views of Earth History. University of Northern Arizona Geology Department. Web Site, Available from: http://jan.ucc. nau.edu/-rcb7/globaltext.html.

Brett-Surman, M.K., 1989. A revision of the Hadrosauridae (Dinosauria: Ornithischia) and their evolution during the Campanian and Maastrichtian. Unpublished PhD Thesis, George Washington University, Washington D.C, p. 272.

Buffetaut, E., Tong-Buffetaut, H., 1993. Tsintaosaurus spinorhinus Young and Tanius sinensis Wiman: a preliminary comparative study of two hadrosaurs from the Upper Cretaceous of China. Comptes Rendus de l'Académie des Sciences, Paris, series 2, Sciences de la Terre et des Planétes 317, 1255-1261.

Buffetaut, E., Tong-Buffetaut, H., 1995. The Late Cretaceous dinosaurs of Shandong, China: old finds and new interpretations. In: Sun, A., Wang, Y. (Eds.), Sixth Symposium on Mesozoic Terrestrial Ecosystems and Biota, Short Papers. China Ocean Press, Beijing, China, pp. 139-142.

Carpenter, K., 1982. The oldest Late Cretaceous dinosaurs in North America? Mississippi Geology 3, 11-17.

Casanovas-Cladellas, M.L., Santafé-Llopis, J.V., Isidro-Llorens, A., 1993. Pararhabdodon isonense n. gen. n. sp. (Dinosauria). estudio mofológico, radiotomográfico y consideraciones biomecanicas. Paleontologia i Evolució 26-27, $121-131$.

Casanovas, M.L., Pereda-Suberbiola, X.P., Santafe, J.V., Weishampel, D.B., 1999a. First lambeosaurine hadrosaurid from Europe: paleobiogeographical implications. Geological Magazine 136, 205-211.

Casanovas, M.L., Pereda-Suberbiola, X.P., Santafe, J.V., Weishampel, D.B., 1999b. A primitive euhadrosaurian dinosaur from the uppermost Cretaceous of the Ager syncline (Southern Pyrenees, Catalonia). Geologie en Mijnbouw 78, 345-356.

Company, J., Galobart, A., Gaete, R., 1998. First data on the hadrosaurid dinosaurs (Ornithischia, Dinosauria) from the Upper Cretaceous of Valencia, Spain. Oryctos 1,121-126.

Cope, E.D., 1870. Synopsis of the extinct batrachia, reptilia and aves of North America. Transactions of the American Philosopical Society 14, 1-252.

Cruzado-Caballero, P., Canudo, J.I., Ruiz-Omeñaca, J.I., 2005. Nuevas evidencias de la presencia de hadrosaurios lambeosaurinos (Dinosauria) en el Maastrichtiense superior de la Península Ibérica (Arén, Huesca). Geogaceta 38, 47-50.

Cruzado-Caballero, P., Canudo, J.I., Ruiz-Omeñaca, J.I., 2007. Los Dinosaurios Hadrosaurios (Ornithischia: Ornithopoda) del Maastrichtiense Superior (Cretácico Superior) de Arén (Huesca, España). IV Jornadas Internacionales de Paleontología de Dinosaurios y su Entorno. Salas de los Infantes, Burgos, pp. 55-56.

Dalla Vecchia, F.M., 2001. Terrestrial ecosystems on the Mesozoic peri-Adriatic carbonate platforms: the vertebrate evidence. In: Leanza, H.A. (Ed.), Proceedings of the VII International Symposium on Mesozoic Terrestrial Ecosystems, Buenos Aires, 1999, Especial 7. Asociación Paleontológica Argentina Publicación, pp. 77-83.

Dalla Vecchia, F.M., 2006. Telmatosaurus and the other hadrosaurids of the Cretaceous.

Davies, K.L., 1983. Hadrosaurian Dinosaurs of Big Bend National Park. MS Thesis, University of Texas at Austin, Austin, Texas, p. 231.

European archipelago. An overview. Natura Nascosta 32 pp. 1-55.

Evans, D.C., 2006. Nasal cavity homologies and cranial crest function in lambeosaurine dinosaurs. Paleobiology 32, 109-125.

Fitch, W.M., 1971. Toward defining the course of evolution: minimum change for a specific tree topology. Systematic Zoology 20, 406-416.

Gaete, R., Prieto-Marquez, A., Riera, V., Oms, O., Galobart, À, 2007. New discoveries of lambeosaurine hadrosaurids from the Tremp Basin (Maastrichtian, Southern Pyrenees): description and stratigraphic setting. In: Liston, J. (Ed.), 55th Symposium of Vertebrate Palaeontology and Comparative Anatomy. The University of Glasgow, pp. 36-37 (abstract of presentations).

Godefroit, P., Lambert, O., 2007. A re-appraisal of Craspedodon lonzeensis Dollo, 1883 from the Upper Cretaceous of Belgium: the first record of a neoceratopsian dinosaur in Europe? Bulletin de l'Institut Royal des Sciences Naturelles de Belgique, Sciences de la Terre 77, 83-93.

Godefroit, P., Dong, Zhi-Ming, Bultynck, P., Li, Hong, Feng, Lu, 1998. Sino-Belgian cooperative program. Cretaceous dinosaurs and mammals from inner mongolia: 1. New Bactrosaurus (Dinosauria: Hadrosauroidea) material from Iren Dabasu (inner mongolia, P.R. China). Bulletin des Institutes Royal des Science Naturalles Belgique 68, 1-70.

Godefroit, P., Zan, Shuqin, Jin, Liyong, 2000. Charonosaurus jiayinensis n. g., n. sp., a lambeosaurine dinosaur from the Late Maastrichtian of Northeastern China. Comptes Rendus de l'Académie des Sciences, Paris, series 2, Sciences de la Terre et des Planétes 330, 875-882.

Godefroit, P., Zan Shuqin, Jin, Liyong, 2001. The Maastrichtian (Late Cretaceous) lambeosaurine dinosaur Charonosaurus jiayinensis from north-eastern China. Bulletin de l'Institut Royal des Sciences Naturelles de Belgique. Sciences de la Terre 71, 119-168.

Godefroit, P., Bolotsky, Y., Alifanov, V., 2003. A remarkable hollow-crested hadrosaur from Russia: an Asian origin for lambeosaurines. Comptes Rendus Palevol 2 , 143-151.

Godefroit, P., Alifanov, V., Bolotsky, Y., 2004a. A re-appraisal of Aralosaurus tuberiferus (Dinosauria, Hadrosauridae) from the Late Cretaceous of Kazakhstan. Bulletin de l'Institut Royal des Sciences Naturelles de Belgique, Sciences de la Terre 74, 139-154.

Godefroit, P., Bolotsky, Y., Van Itterbeeck, J., 2004b. Amurosaurus riabinini, a Late Cretaceous lambeosaurine dinosaur from far eastern Russia. Acta Palaeontologica Polonica 49, 585-618.

Head, J.J., 2001. A reanalysis of the phylogenetic position of Eolambia caroljonesa (Dinosauria: Iguanodontia). Journal of Vertebrate Paleontology 21, 392-396.

Head, J.J., Kobayashi, Y., 2001. Biogeographic histories and chronologies of derived iguanodontians. 1999. In: Leanza, H.A. (Ed.), Proceedings of the VII International Symposium on Mesozoic Terrestrial Ecosystems, Especial 7. Asociación Paleontológica Argentina Publicación, Buenos Aires, pp. 107-111.

Hopson, J.A., 1975. The evolution of cranial display structures in hadrosaurian dinosaurs. Paleobiology 1, 21-44.

Horner, J.R., Weishampel, D.B., Forster, C.A., 2004. Hadrosauridae. In: Weishampel, D.B., Dodson, P., Osmólska, H. (Eds.), The Dinosauria, Second ed. University of California Press, Berkeley, California, pp. 438-463.

Huelsenbeck, J.P., Ronquist, F., 2001. MRBAYES: Bayesian inference of phylogeny. Bioinformatics 17, 754-755.

Hu, C., Cheng, Z., Pang, Q., Fang, X., 2001. Shantungosaurus Giganteus. Hauyu Nature Trade, China, Beijing, p. 135.

Laurent, Y., Le Loeuff, J., Buffetaut, E., 1997. Les Hadrosauridae (Dinosauria, Ornithopoda) du Maastrichtien supérieur des Corbières orientales (Aude, France). Revue de Paléobiologie 16, 411-423.

Laurent, Y., Calvin, L., Bilotte, M., 1999. Découverte d'un gisement a vertébrés dans le Maastrichtien supérieur des Petites-Pyrénées. Comptes Rendus de l'Académie des Sciences, Paris, series 2, Sciences de la Terre et des Planétes 328, 781-787.

Lehman, T.M., 2001. Late Cretaceous dinosaur provinciality. In: Tanke, D.H., Carpenter, K. (Eds.), Mesozoic Vertebrate Life. Indiana University Press, Bloomington, Indiana, pp. 310-328.

Lewis, P.O., 2001. A likelihood approach to estimating phylogeny from discrete morphological character data. Systematic Biology 50, 913-925.

Le Loeuff, J., Buffetaut, E., Martin, M., Martín, V., Tong, H., 1993. Découverte d'Hadrosauridae (Dinosauria, Ornithischia) dans le Maastrichtien des Corbières (Aude, France). Comptes Rendus de l'Academie des Sciences Naturelles, Paris, series 2, Sciences de la Terre et des Planétes 316, 1023-1029.

Le Loeuff, J., Buffetaut, E., Martin, M., 1994. The last stages of dinosaur faunal history in Europe: a succession of Maastrichtian dinosaur assemblages from the Corbières (Southern France). Geological Magazine 131, 625-630.

Lindgren, J., Currie, P.J., Siverson, M., Rees, J., Cederström, P., Lindgren, F., 2007. The first neoceratopsian dinosaur remains from Europe. Palaeontology 50, 929-937.

López-Martínez, N., Canudo, J.I., Ardèvol, L., Superbiola, X.P., Orue-Etxebarria, X., Cuenca-Bescós, G., Ruiz-Omeñaca, J.I., Murelaga, X., Feist, M., 2001. New dinosaurs sites correlated with upper Maastrichtian pelagic deposits in the Spanish Pyrenees: implications for the dinosaur extinction pattern in Europe. Cretaceous Research 22, 41-61.

Lund, E.K., Gates, T.A. 2006. A historical and biogeographical examination of hadrosaurian dinosaurs. In Lucas, S.G., Sullivan, R.M. (Editors). Late Cretaceous Vertebrates from the Western Interior. New Mexico Museum of Natural History Bulletin 35 pp. 263-276.

Maddison, D.R., Maddison, W.P., 2003. MacClade Version 4.0. Sinauer Associates, Inc., Sunderland, Massachusetts.

Maddison, W.P., Donoghue, M.J., Maddison, D.R., 1984. Outgroup analysis and parsimony. Systematic Zoology 33, 83-103.

Martín, M., Gaete, R., Galobart, À., Riera, V., Oms, O., 2007. A new hadrosaurian bonebed in the Maastrichtian of the southern Pyrenees: a stratigraphic and taphonomic approach. In: Liston, J. (Ed.), 55th Symposium of Vertebrate Palaeontology and Comparative Anatomy. The University of Glasgow, p. 40 (abstract of presentations).

Nopcsa, F., 1903. Dinosaurierreste aus Siebenbürgen (schädel von Limnosaurus transsylvanicus nov. gen. et spec.). Denkschriften der Kaiserlichen Akademie der Wissenschaften in Wien, Mathematisch-Naturwissenschaftliche Klasse 68, 555-591.

Nopcsa, F., 1923. On the geological importance of the primitive reptilian fauna in the uppermost Cretaceous of Hungary; with a description of a new tortoise (Kallokibotium). Quarterly Journal of the Geological Society of London 79, 100-116. 
Nopcsa, F., 1934. The influence of geological and climatological factors on the distribution of non-marine fossil reptiles and Stegocephalia. Quarterly Journal of the Geological Society of London 90, 76-140.

Norman, D.B., 1986. On the anatomy of Iguanodon atherfieldensis (Ornithischia: Ornithopoda). Bulletin de l'Institut Royal des Sciences Naturelles de Belgique, Sciences de la Terre 56, 281-372.

Norman, D.B., 2002. On Asian ornithopods (Dinosauria: Ornithischia). 4. Probactrosaurus Rozhdestvensky, 1966. Zoological Journal of the Linnean Society 136, 113-144.

Paris, J.P., Taquet, P., 1973. Découverte d'un fragment de dentaire d'hadrosaurien (reptile Dinosaurien) dans la Crétacé supérieur des Petites Pyrénées (HauteGaronne). Bulletin du Muséum National d'Histoire Naturelle 3, 17-27.

Parks, W.A., 1923. Corythosaurus intermedius, a New Species of Trachodont Dinosaur Geological Series 15, 5-57. University of Toronto Studies.

Prieto-Marquez, A. 2008. Phylogeny and Historical Biogeography of Hadrosaurid Dinosaurs. Unpublished PhD Dissertation, Florida State University, Tallahassee, Florida, p. 936.

Prieto-Márquez, A., Gaete, R., Rivas, G., Galobart, À, Boada, M., 2006. Hadrosauroid dinosaurs from the Late Cretaceous of Spain: Pararhabdodon isonensis revisited and Koutalisaurus kohlerorum, gen. et sp. nov. Journal of Vertebrate Paleontology 26, 929-943.

Prieto-Marquez, A., Gaete, R., Galobart, À., Riera, V., Oms, O., 2007. New data on European Hadrosauridae from the latest Cretaceous of Spain. Journal of Vertbrate Paleontology 27, 131A.

Ronquist, F., 1996. DIVA Version 1.1. Computer Program and Manual Available by Anonymous FTP from Uppsala University (ftp.uu.se or ftp.systbot.uu.se).

Ronquist, F., 1997. Dispersal-Vicariance analysis: a new approach to the quantification of historical biogeography. Systematic Biology 46, 195-203.

Sereno, P.C., 1986. Phylogeny of the bird-hipped dinosaurs (Order Ornithischia). National Geographic Research 2, 234-256.

Swofford, D.L., 2002. PAUP*. Phylogenetic Analysis Using Parsimony (*and Other Methods). Version 4.0b10. Sinauer Associates, Sunderland, Massachusetts.

Taquet, P., 1991. The status of Tsintaosaurus spinorhinus Young, 1958 (Dinosauria). Extended abstracts. In: Kielan-Jaworowska, Z., Heintz, N., Nakrem, H.A. (Eds.) Fifth Symposyum of Mesozoic Terrestrial Ecosystems and Biota, 364. Paleontological Museum, Oslo, pp. 63-64.
Wagner, J.R., 2001. The hadrosaurian dinosaurs (Ornithischia: Hadrosauria) of Big Bend National Park, Brewster County, Texas, with Implications for Late Cretaceous Paleozoogeography. Unpublished MS Thesis, Texas Tech University, Lubbock, Texas, p. 417.

Wagner, J.R., 2004. Hard-tissue homologies and their consequences for interpretation of the cranial crests of lambeosaurine dinosaurs (Dinosauria: Hadrosauria). Journal of Vertebrate Paleontology 24, 125A-126A.

Wagner, J.R., Lehman, T., 2009. An enigmatic new lambeosaurine hadrosaur (Reptilia: Dinosauria) from the Upper Shale Member of the Campanian Aguja Formation of Trans-Pecos Texas. Journal of Vertebrate Paleontology 29 605-611.

Weishampel, D.B., 1981. The nasal cavity of lambeosaurine hadrosaurids (Reptilia: Ornithischia): comparative anatomy and homologies. Journal of Paleontology 55, 1046-1057.

Weishampel, D.B., Horner, J.R., 1990. Hadrosauridae. In: Weishampel, D.B. Dodson, P., Osmólska, H. (Eds.), The Dinosauria. University of California Press, Berkeley, pp. 534-561.

Weishampel, D.B., Grigorescu, D., Norman, D.B., 1993. Telmatosaurus transsylvanicus from the Late Cretaceous of Romania: the most basal Hadrosaurid Dinosaur. Palaeontology 36, 361-385.

Weishampel, D.B., Barrett, P.M., Coria, R.A., Le Loeuff, J., Xing, Xu, Xijin, Zhao, Sahni, A., Gomani, E.M.P., Noto, C.R., 2004. Dinosaur distribution. In: Weishampel, D.B., Dodson, P., Osmolska, H. (Eds.), The Dinosauria, Second ed University of California Press, Berkeley, California, pp. 517-606.

Wiley, E.O., 1981. Phylogenetics: The Theory and Practice of Phylogenetic Systematics. John Wiley and Sons, New York, p. 439.

Wilkinson, M., Benton, M.J., 1995. Missing data and rhynchosaur phylogeny. Historical Biology 10, 137-150.

Witmer, L.M., 1997. The evolution of the antorbital cavity of archosaurs: a study in soft-tissue reconstruction in the fossil record with an analysis of the function of pneumaticity. Society of Vertebrate Paleontology Memoir 3. Journal of Vertebrate Paleontology 16, 1-73.

Young, C.-C., 1958. The dinosaurian remains of Laiyang, Shantung. New Series C. Palaeontologica Sinica 16, 53-138. 